\title{
Do One Good Thing for Bees Today: Twenty-five Facts about North American Wild Bees ${ }^{1}$
}

\author{
Jorge A. Santiago-Blay, Rapporteur ${ }^{2}$
}

Wild bees are not honeybees, Apis mellifera. Wild bees do not have hives, instead many species nest in the ground, and most of them cannot sting. In fact, there are about 4,000 different species of bees in North America, some of which do not have scientific names. Almost all wild bees are single moms, feeding their young pollen from selected types of plants.

How can we protect wild bees? Protect their plants. Wild bees use pollen and nectar from our native plant communities. The more diversity of plants, the more bees are protected. Shift your lawn area to bee area by planting blooming native plants and shrubs. This is something we all can participate in.

The images reproduced below come from a poster entitled, 25 Facts about Bees, prepared for the United Nations World Bee Day by Sam Droege. Additional information on World Bee Day can be found here: https://www.un.org/en/events/beeday/ and https://www.worldbeeday.org/en/. The original jpg version of the poster and/or individual images can be freely downloaded from: ftp://ftpext.usgs.gov/pub/er/md/laurel/Droege/25\%20Facts\%20Bees/ (login, anonymous; password, guest). Feel free to pass them along to others. Follow our images and blogs@USGSBIML on Instagram and Tumblr.
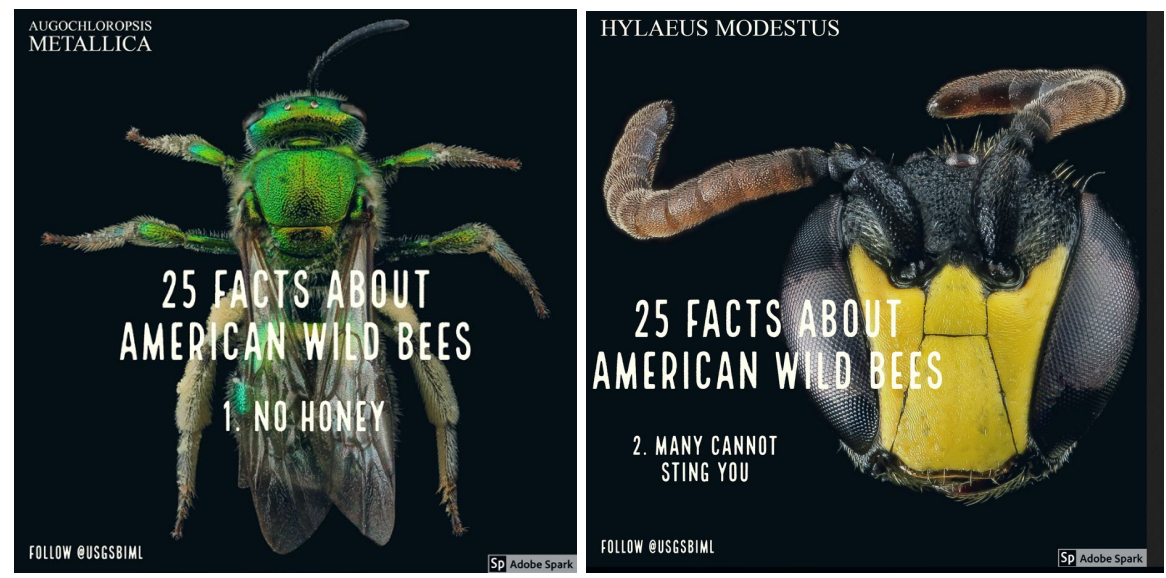

\footnotetext{
${ }^{1}$ Submitted and accepted on May 20, 2019. Last changes received on May 30, 2019.

2217 Wynwood Road, York, Pennsylvania 17402 USA. Email: blayi@gmail.com
}

DOI: 10.9784/LEB6(4)SantiagoBlay.01

Electronically available on May 30, 2019. Mailed on May 31, 2019. 

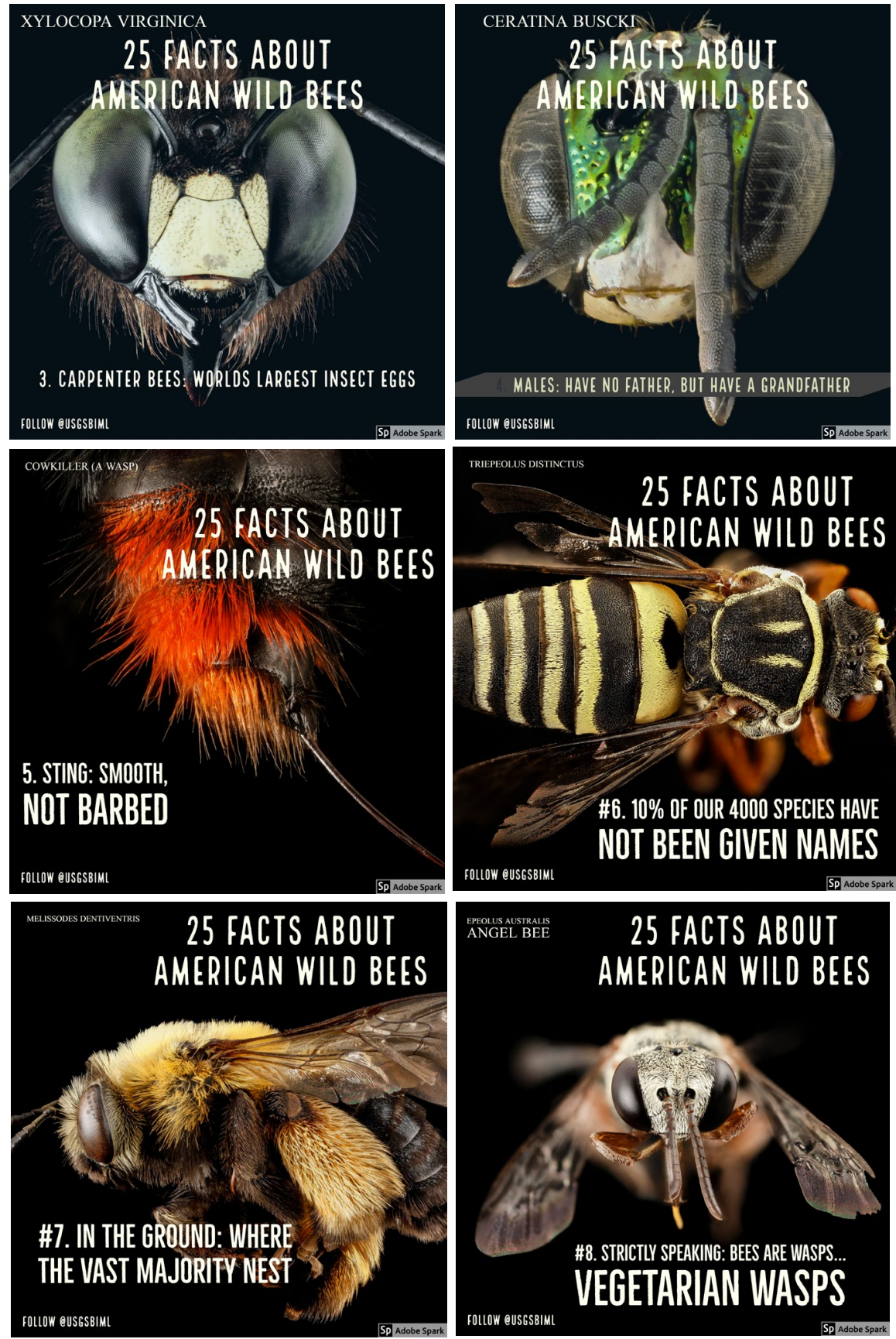

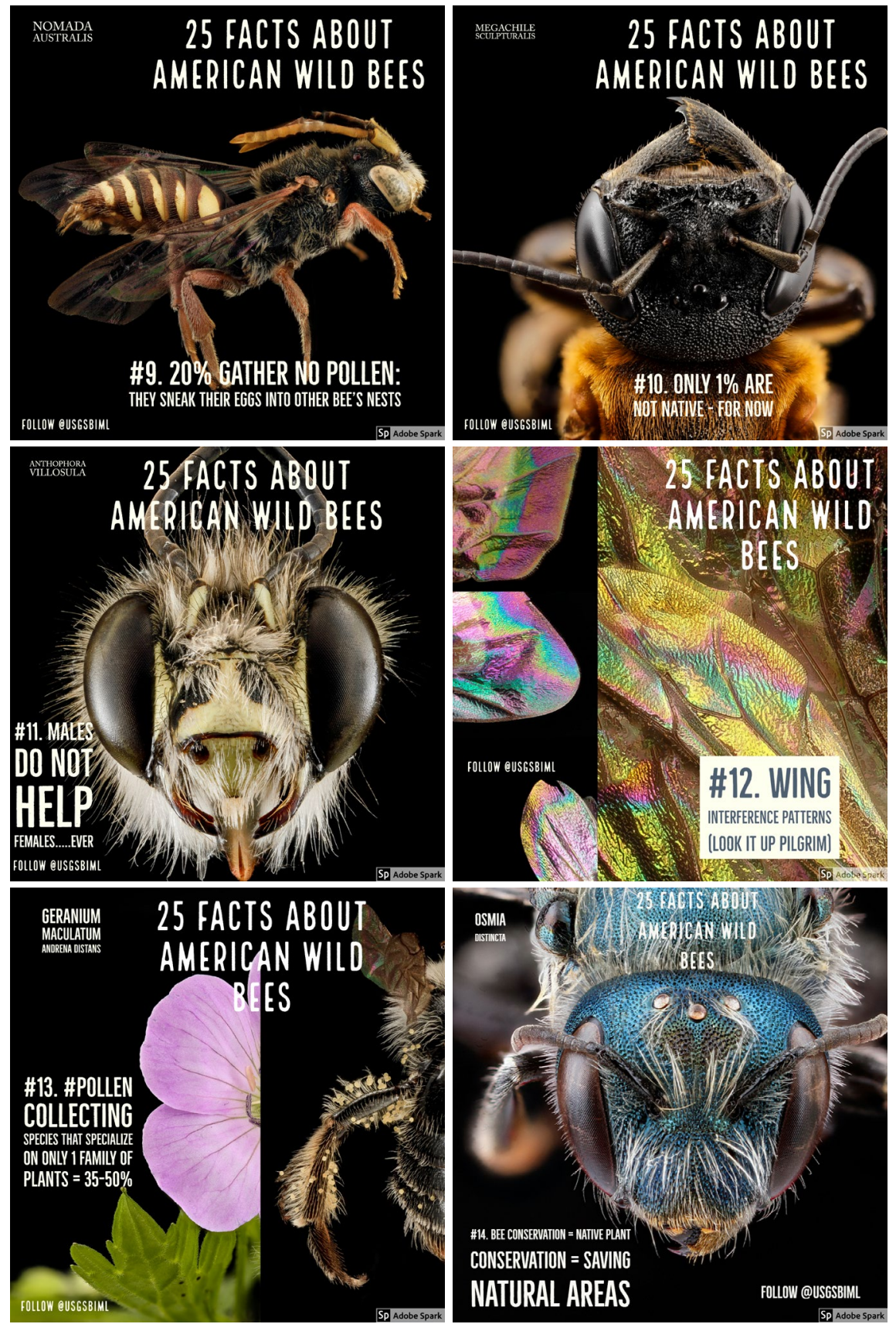

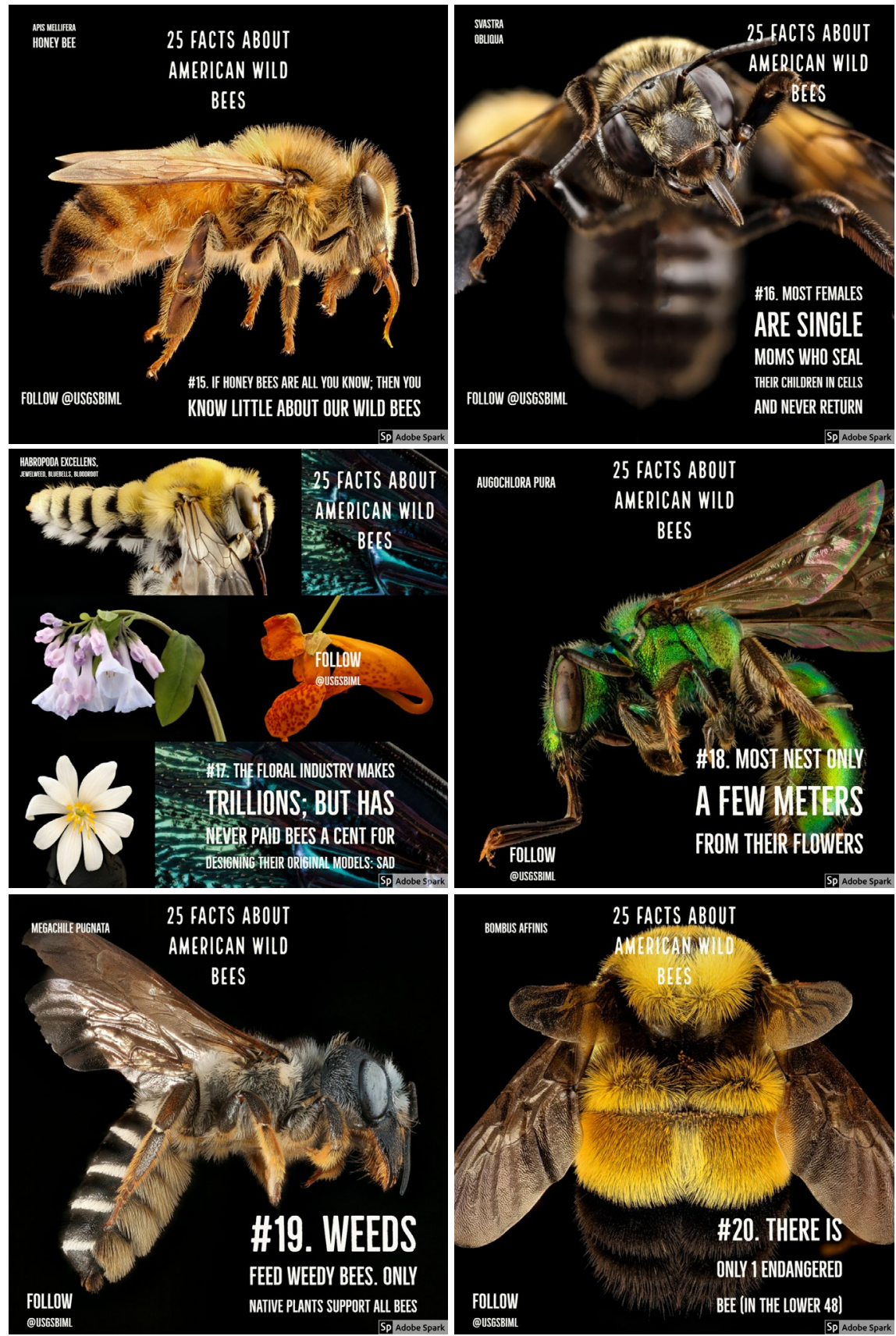

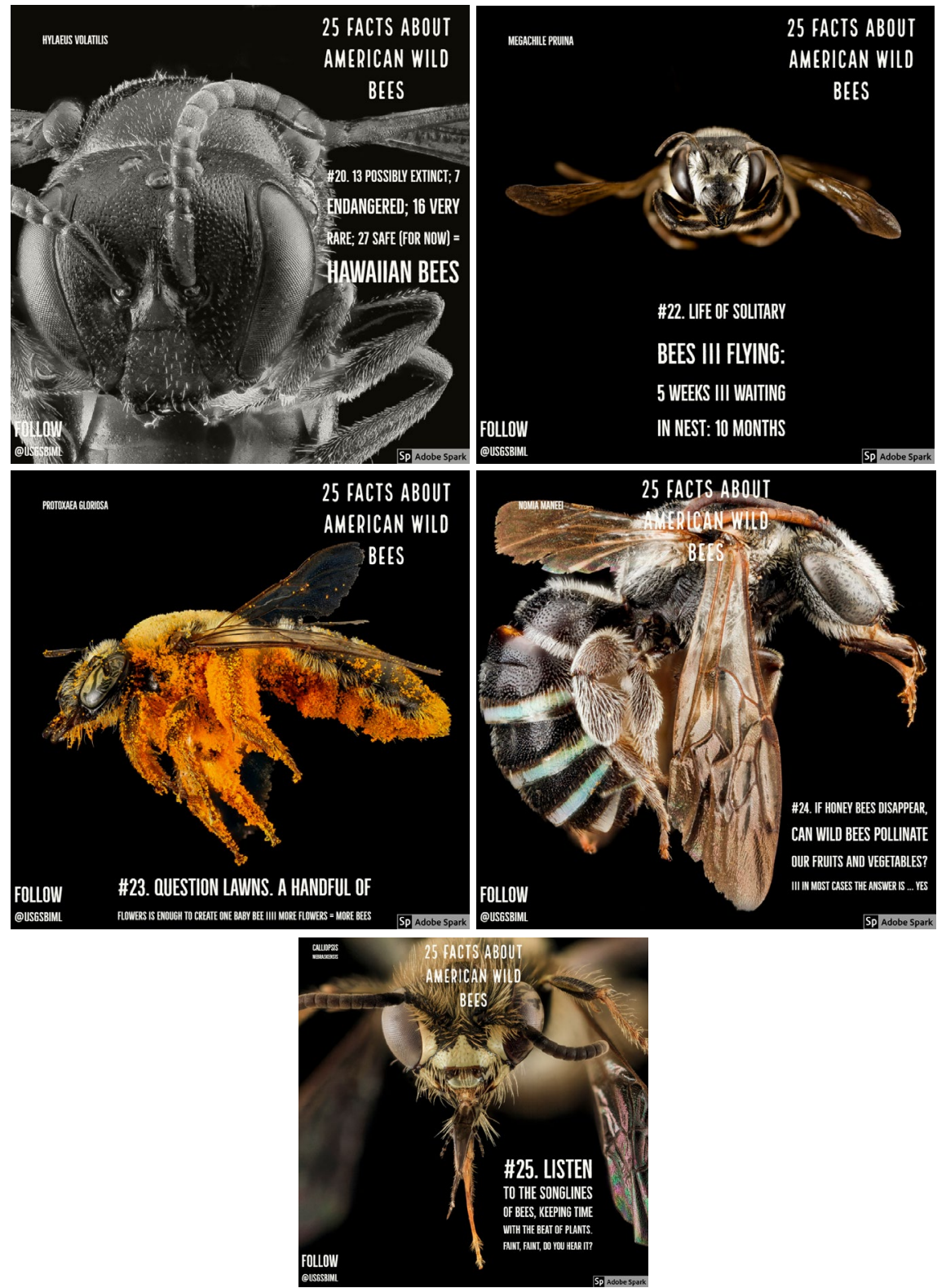

Acknowledgments

Mr. Sam Droege (Patuxent Wildlife Research Center, 12100 Beech Forest Drive, Laurel, Maryland 20708 USA. E-mail: sdroege@usgs.gov) provided all the information on which this report is based. 